\title{
Excremental Study of Lift/Drag Ratio Enhancement Using Continuous Normal Suction
}

\author{
Taha A. Abdullah \\ Assistant Lecturer \\ Mechanical Dep.
}

\author{
Dr. Laith M. Jasim \\ Lecturer \\ Mechatronics Dep.
}

College of Engineering -University of Mosul

\author{
Dr. Amir S. Dawood \\ Assistant Professor \\ Mechanical Dep.
}

\begin{abstract}
An experimental work of continuous normal suction from the wing upper surface effects on the aerodynamic forces is carried out, as well as, the effect of normal suction slot channels location and the mass flow rate sucked strength are involved in this study. The wing model with NACA-0015 has been made to achieve normal suction from the wing upper surface by means of four slot channels. The satisfaction of the suction is done by using vacuum pump. The tests are to be done for incompressible flow over wing with and without a continuous normal suction for three different angle of attack 8, 12 and 16 Deg., and for three different Reynolds numbers $13.6 \times 10^{4}, 20.4 \times 10^{4}$ and $24.5 \times 10^{4}$. The results showed that the continuous normal suction can significantly increase the lift to drag force ratio, and this ratio is increasing more as the strength of the suction increases.
\end{abstract}

Keywords : Aerodynamic - Incompressible Flow - Boundary Layer Control - Normal Suction- Experimental work - Lift and Drag Coefficient

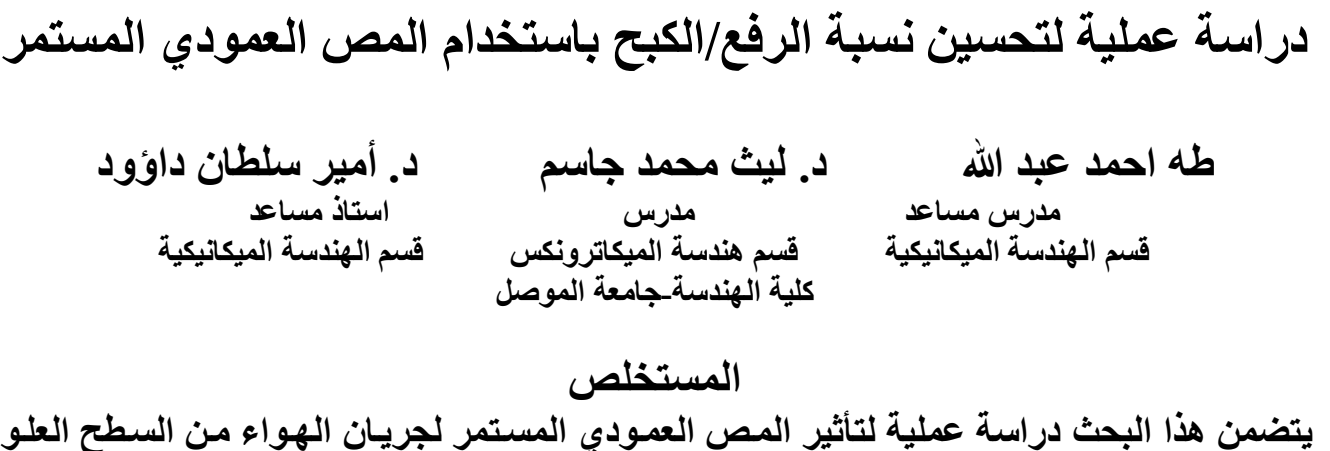

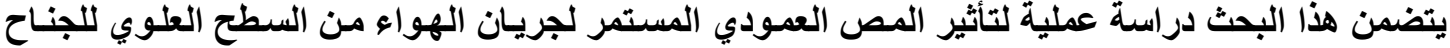

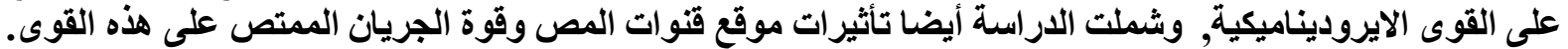

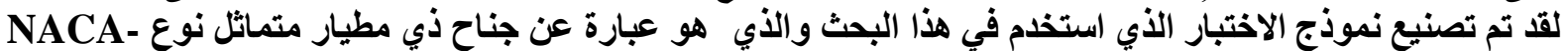

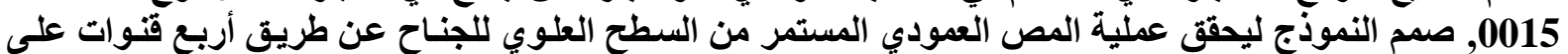

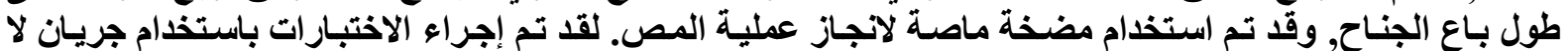

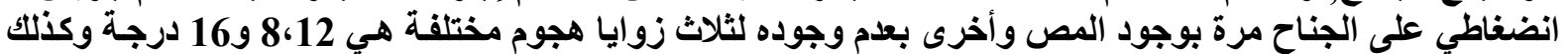

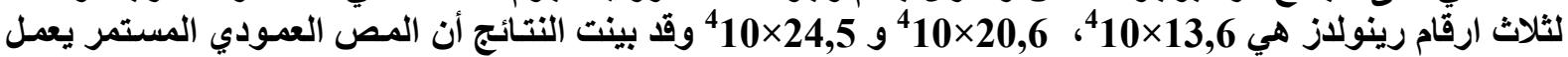

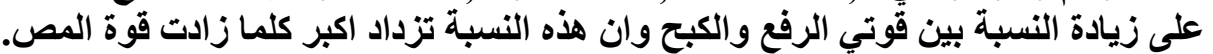




\section{List of Symbols}

\begin{tabular}{|c|l|c|}
\hline Symbol & \multicolumn{1}{|c|}{ Description } & Unit \\
\hline$c$ & Airfoil chord & $m$ \\
\hline$C_{D}$ & Drag coefficient & - \\
\hline$C_{L}$ & Lift coefficient & - \\
\hline$C_{L w s}$ & Lift coefficient with suction & - \\
\hline$C_{L w o s}$ & Lift coefficient without suction & - \\
\hline$C_{D w s}$ & Drag coefficient with suction & - \\
\hline$C_{D w o s}$ & Drag coefficient without suction & - \\
\hline$C_{L} / C_{D}$ & Lift to drag coefficient ratio & - \\
\hline$D$ & Drag force & $\mathrm{N}$ \\
\hline$L$ & Lift force & $\mathrm{N}$ \\
\hline$\dot{m}$ & Total mass flow rate & $\mathrm{kg} / \mathrm{s}$ \\
\hline$\dot{m}_{s}$ & Suction mass flow rate & $\mathrm{kg} / \mathrm{s}$ \\
\hline$\dot{M}_{s}$ & Percentage of suction mass flow rate to the total & - \\
\hline$R e$ & mass flow rate & - \\
\hline$S$ & Reynolds number & - \\
\hline$V$ & Wing area & $\mathrm{m} / \mathrm{m} / \mathrm{m}^{3}$ \\
\hline$\rho$ & Flow velocity & - \\
\hline$\Delta C_{L s}$ & Lift coefficient increment due to suction & - \\
\hline$\Delta C_{D s}$ & Drag coefficient increment due to suction & \\
\hline$\alpha$ & Angle of attack & - \\
\hline
\end{tabular}

\section{Introduction:}

The flow separation is mostly an undesirable phenomenon, because it entails large energy losses and in most applications adversely affects the aerodynamic loads in the form of lift loss and drag increase. Further, in external flow the separation flow from airfoil or cylinder as examples, can cause damage in flow structure through the oscillations of the flow, which leads to increase the drag and noise. Therefore, there is a strong tendency to delay or manipulate the occurrence of flow separation. Hence, the separation control is of great importance to most of the systems involving fluid flow. The control of flow separation, historically referred to as boundary-layer control, is probably the oldest and most economically important, and has become very important in present time, in particular in the field of aeronautical engineering. However, the flow control modern development eras were reviewed broadly by Gad-el-Hak [1] in 1996.

Wall suction and blowing have been encountered in many aeronautical engineering problems such as delaying or preventing the separation from the upper airfoil surface, and enhance airfoil wake flow structure. The results include lift enhancement and flow-induced noise suppression. Generally, the wall suction/blowing may be applied either normally or tangentially to the wall, farther, may be applied continuously or periodically. 


\section{Why boundary layer control is very important!}

From a paper by Boing aerodynamicists [2] in 1991:

- A $1.5 \%$ increase in maximum lift coefficient is equivalent to a $6600 \mathrm{Ib}$ increase in payload at a fixed approach speed.

- A $1.0 \%$ increase in take-off Lift/Drag (L/D) is equivalent to a $2800 \mathrm{Ib}$ increase in payload or a $159 \mathrm{Km}$ increase in range.

Shojaefard et al., 2005, [3], presented a numerical study concerning flow control by suction and injection. The case studied was the flow field over a subsonic airfoil with four suction and injection slots on the suction side of the airfoil. A commercial CFD code, the FLUENT, was used in this study. The effect of suction and injection on aerodynamic coefficients was investigated. The results showed that the surface suction can significantly increase the lift coefficient. The injection decreases the skin friction. Atik et al., 2005, [4], studied the suction near the leading edge as a means of controlling separation and thereby inhibiting dynamic stall, high-speed incompressible flow past a thin airfoil in a uniform stream was considered, by using steady and unsteady boundary-layer solutions. It was determined that substantial delays in separation can be achieved even when the suction is weak, provided that the suction is initiated at an early stage. Ge-Cheng et al., 2006, [5], compared the airfoil with injection only with the co-flow jet (CFJ) airfoil with both injection and suction with the similar injection momentum coefficient. A high energy jet is injected near the leading edge tangentially and the same amount of mass flow is sucked in near the trailing edge. The Fluent CFD software was used. The CFD simulations indicated that the suction of the CFJ airfoil significantly enhances the results of lift, drag and stall angle of attack. Laith M. Jasim, 2008, [6], presented a numerical simulation study of unsteady incompressible laminar flow over a NACA 0015 airfoil with and without a continuous wallnormal suction and blowing as an active boundary layer control technique. In controlling the flow, the case of study is the flow field over an airfoil with a four holes which are penetrated the airfoil from the upper surface to the lower surface and through which a part from primary flow is sucked from upper surface, and then blowing it through same holes from lower surface. The use of continuous wall-normal suction and blowing from upper and lower surface of the airfoil, respectively, is an effective idea to prevent or delay the flow separation and enhance airfoil wake flow structure.

The present work is an experimental, applying a continuous normal suction rate from upper wing surface to enhance the lift, drag force and their ratio.

\section{Experimental Work}

In this work, an experimental investigation has been done to study the continuous normal suction effect of air flow from the upper surface of wing on the lift and drag coefficients and their ratio.

All tests have been done, using a subsonic wind tunnel (Armfield Subsonic Wind Tunnel C2) in the mechanical engineering department/university of Mosul. The velocity range $(0-25 \mathrm{~m} / \mathrm{s})$, test section $(200 \times 200 \mathrm{~mm})$ and the range of two component balance $(0-7 \mathrm{~N})$ and $(0-2.5 \mathrm{~N})$ for measuring lift and drag forces.

The lift and drag coefficient are determine.

$$
\begin{aligned}
& C_{L}=\frac{L}{0.5 \rho V^{2} S} \\
& C_{D}=\frac{D}{0.5 \rho V^{2} S}
\end{aligned}
$$


The wooden wing model (airfoil NACA0015) with wing spans $95 \mathrm{~mm}$ and chord of $200 \mathrm{~mm}$. This wing was made to achieve normal suction from the wing upper surface by means of four slot channels, Fig.(1). The number and the location of these channels can be controlled by closing some of them according to the required measurements for the four cases.

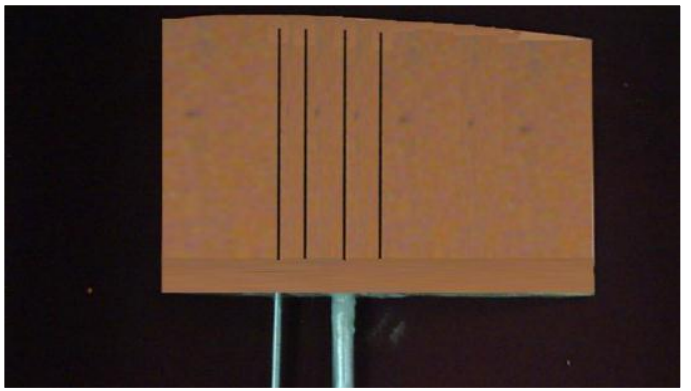

Figure (1) Wing Model.

The distribution and dimensions (Percentage of chord length) of the slot channels are shown in Fig.(2). These suction channels are separated from each other within the wing, and connected to a main channel. The four slot channels are consisted of two sets, forward set and down set, and each set includes two slot channels.

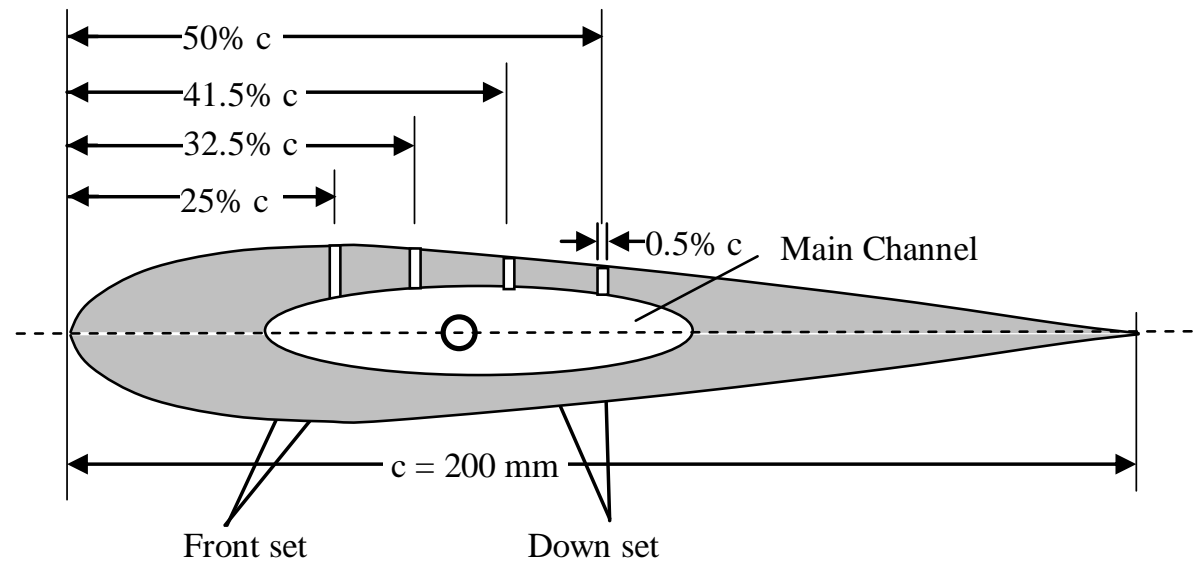

Figure (2) Schematic of Airfoil Model.

The satisfaction of the suction is done by using vacuum pump, connected the main channel by rubber tubes, Fig.(3). The testing wing is fixed to the two component balance inside the wind tunnel test section, and connected to the vacuum pump.

The test are to be done for three different angle of attack $(8,12,16$ Deg. $)$, and for three different flow velocities $(10,15,18 \mathrm{~m} / \mathrm{s})$ with and without suction. The Reynolds numbers (Re) corresponding to flow velocities of 10,15 and 18 $\mathrm{m} / \mathrm{s}$ are $13.6 \times 10^{4}, 20.4 \times 10^{4}$ and $24.5 \times 10^{4}$, respectively.

The percentages of suction mass flow rate to the total mass flow rate inside the wind tunnel $\left(\dot{M}_{s}=\dot{m}_{s} / \dot{m}\right)$ for each velocity are found as

follows; for the test velocity $10 \mathrm{~m} / \mathrm{s}$ and suction from the four channels (the two sets) and two

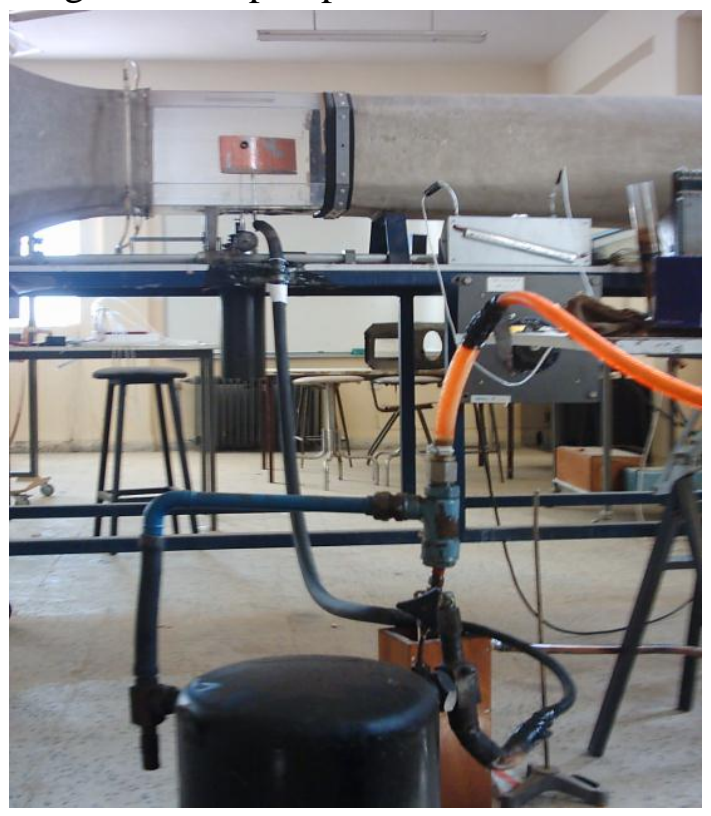

Figure (3) Experimental Rig. 
channels (forward or down set) are $1.085 \%$ and $1.06 \%$ respectively, however for the test velocity $15 \mathrm{~m} / \mathrm{s}$ it have been found that the percentages of mass flow are

$0.72 \%$ and $0.70 \%$ respectively, and for velocity $18 \mathrm{~m} / \mathrm{s}$ are $0.602 \%$ and $0.59 \%$ respectively.

\section{Results and Discussion}

Figure (4) shows the relationship between the lift coefficient and angle of attack for the four different cases, including without and with suction from the four slot channels, also from the forward set and down set channels for three different Reynolds numbers $13.6 \times 10^{4}$, $20.4 \times 10^{4}$ and $24.5 \times 10^{4}$. From Fig. (4), it can be observed that the lift coefficient increase as $\dot{M}_{s}$ increase from the upper surface of the wing. However, when $\dot{M}_{s}$ kept constant (suction from the forward set or down set channels), the increasing in the lift coefficient $\Delta C_{L s}$ due to suction from the front set channels is found to be higher than that when the suction from the down set channels as shown in Figs. (4-a and b), where

$$
\Delta C_{L s}=C_{L w s}-C_{L w o s}
$$

As the Reynolds number increase as shown in Fig. (4-c) and $\dot{M}_{s}$ is kept constant, it is found that the lift coefficient increment due to suction $\left(\Delta C_{L s}\right)$ from the down set channels is greater than that when the suction is from the forward set channels. Also from Fig. (4), it can be seen that $\Delta C_{L s}$ decreases as the Reynolds number increases, for example, at an angle of $8^{\circ}$ and $R e=13.6 \times 10^{4}$, the value of lift coefficient without suction $C_{L w o s}=0.4$ while its value with suction for the four slot channel $C_{L w s}=0.5$, therefore $\Delta C_{L s}=0.1$. When $R e=24.5 \times 10^{4}$ for the same angle $8^{\circ}$, its found $C_{L w s}=0.36$ and $C_{L w o s}=0.32$, then $\Delta C_{L s}=0.04$, this value has been found to be less at $R e=13.6 \times 10^{4}$.

Figure (5) shows the relationship between the drag coefficient and the angle of attack for the same cases without and with suction from the four slot channels, also for two forward and down sets channels for three different Reynolds numbers $13.6 \times 10^{4}, 20.4 \times 10^{4}$ and $24.5 \times 10^{4}$. It can be seen from Fig.(5) that the drag coefficient increases as $\dot{M}_{s}$ increases. However, when $\dot{M}_{s}$ is kept constant, the drag coefficient due to suction from the forward set channels is higher than that when the suction from the down set channels as shown in Figs. (5- a and $\mathrm{b})$, where

$$
\Delta C_{D s}=C_{D w s}-C_{D w o s}
$$

However, when the value of $\dot{M}_{s}$ is constant, the magnitude of $\Delta C_{D s}$ from the down set channels is greater than that when the suction is from the forward set channels as shown in Fig. (5-c). It also can be seen from Fig. (5), that the value of $\Delta C_{D s}$ decreases as the Reynolds number increases. For example, when the angle is $8^{\circ}$ and $R e=13.6 \times 10^{4}$, the $C_{D \text { wos }}=0.16$ and $C_{D w s}=0.19$ then $\Delta C_{D s}=0.03$. When $R e=24.5 \times 10^{4}$ for the same angle $8^{\circ}$, it has found that $C_{D w s}=0.14$ and $C_{D w o s}=0.13$, then $\Delta C_{D s}=0.01$, this value has been found to be less at $R e=13.6 \times 10^{4}$.

The ratio of lift coefficient to drag coefficient $C_{L} / C_{D}$ is an important parameter for aircraft flying performance indication (including take off and landing velocity, airport runway distance, aircraft maneuver and fuel consumption). However, for higher value of $C_{L} / C_{D}$, the flying characteristics are improved. 

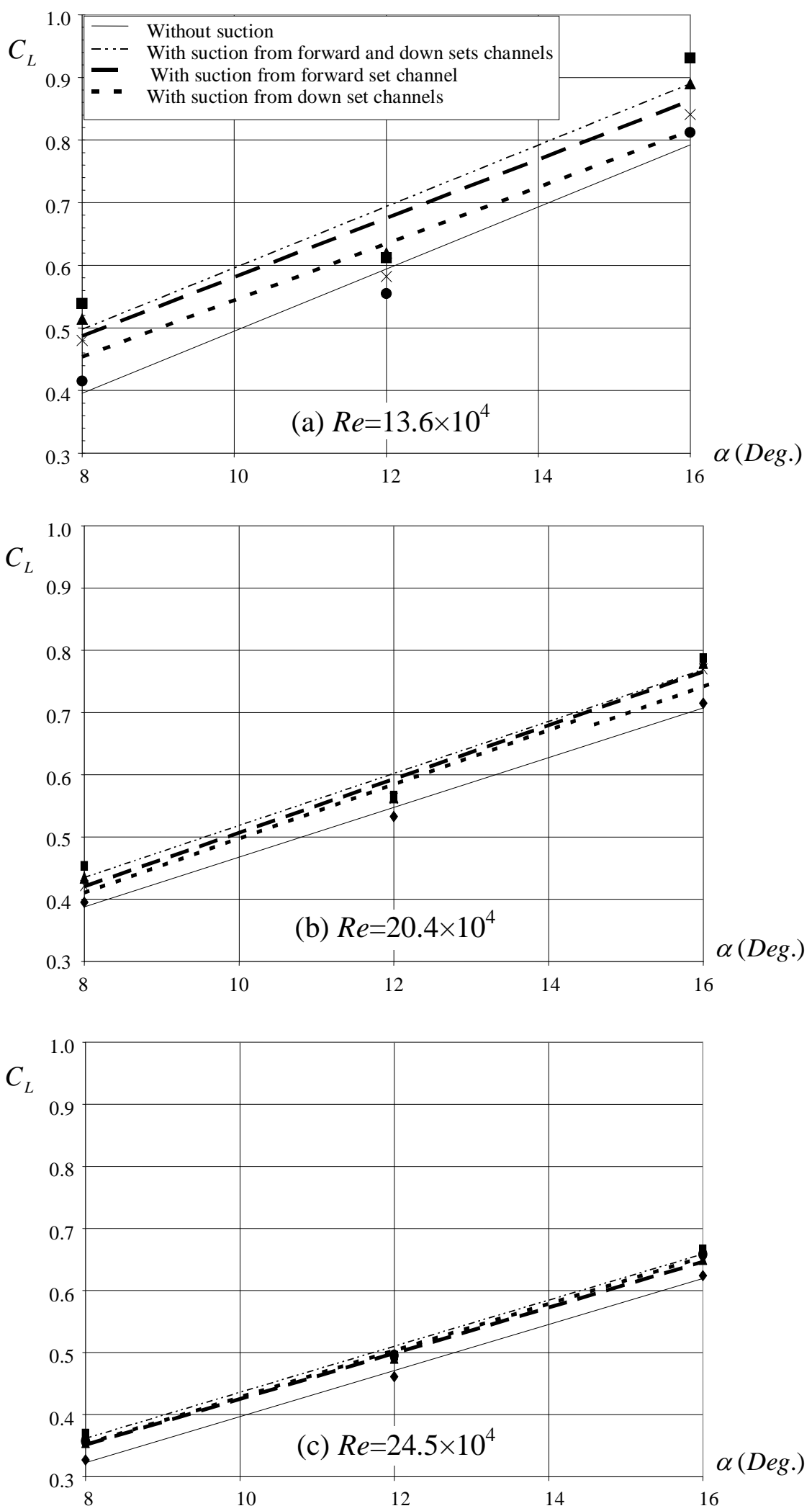

Fig. (4) Lift coefficient versus angle of attack. 

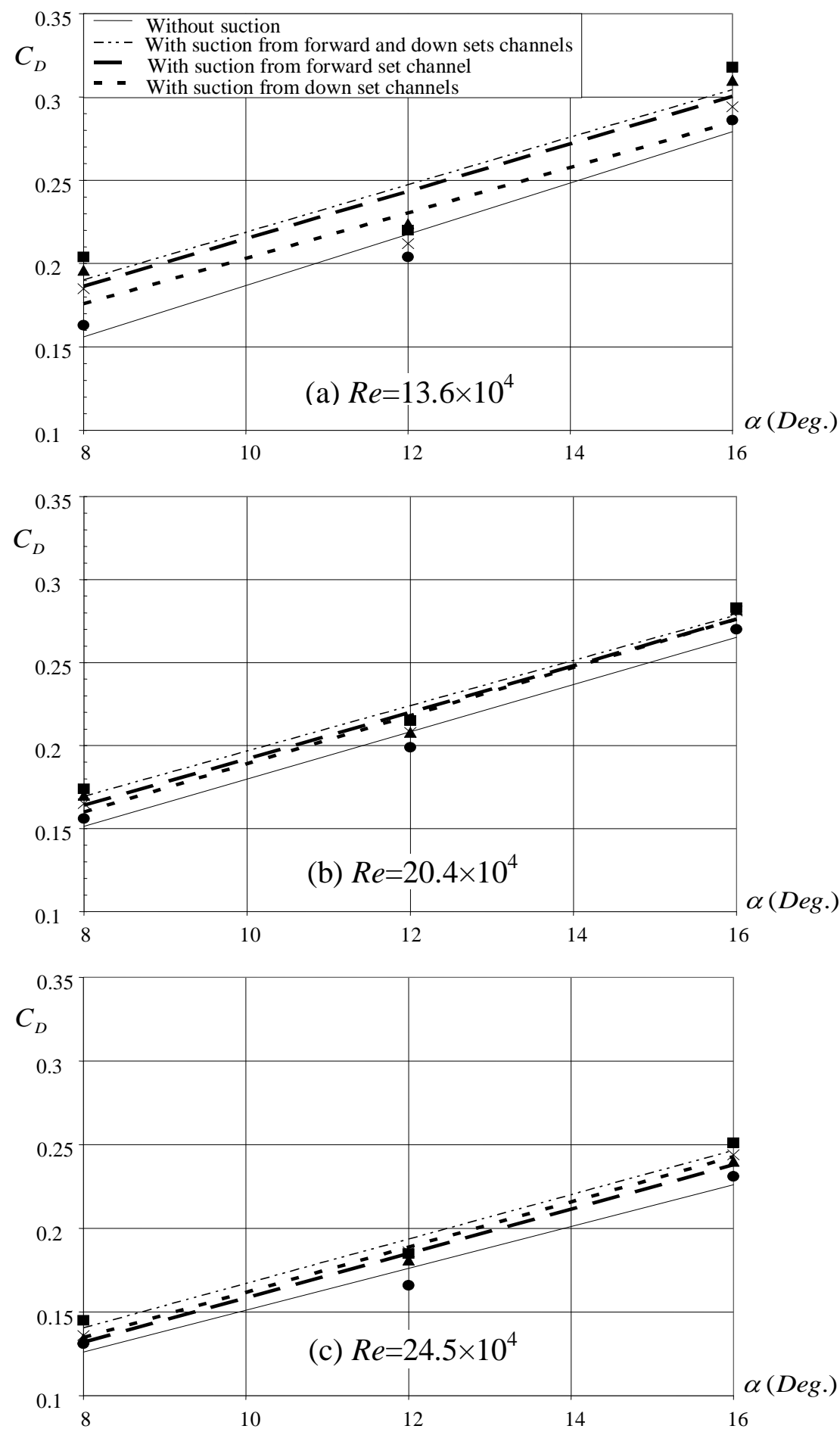

Fig. (5) Drag coefficient versus angle of attack.

Figure (6) shows the relation between $C_{L} / C_{D}$ and angle of attack for different Reynolds numbers $13.6 \times 10^{4}, 20.4 \times 10^{4}$ and $24.5 \times 10^{4}$ and for the four experimental cases. It can be seen from this figure that this ratio $C_{L} / C_{D}$ increases as $\dot{M}_{s}$ increase.

Also from figure (6), it can be noted that the amount of increase in $C_{L} / C_{D}$ decrease as the Reynolds number increase, where 


$$
\Delta\left(C_{L} / C_{D}\right)_{s}=\left(C_{L} / C_{D}\right)_{w s}-\left(C_{L} / C_{D}\right)_{\text {wos }}
$$

For example at an angle of $8^{\circ}$ and $R e=13.6 \times 10^{4}$ the value of $\left(C_{L} / C_{D}\right)_{\text {wos }}=2.56$, and $\left(C_{L} / C_{D}\right)_{w s}=2.64$, then the value of $\Delta\left(C_{L} / C_{D}\right)_{s}=0.08$. By keeping the same angle of attack at $8^{\circ}$ and Reynolds number changed to $24.5 \times 10^{4}$, the value of $\left(C_{L} / C_{D}\right)_{\text {wos }}=2.515$, and $\left(C_{L} / C_{D}\right)_{w s}=2.562$, hence $\Delta\left(C_{L} / C_{D}\right)_{s}=0.047$. Surely, this value has been found to be much less at $R e=13.6 \times 10^{4}$
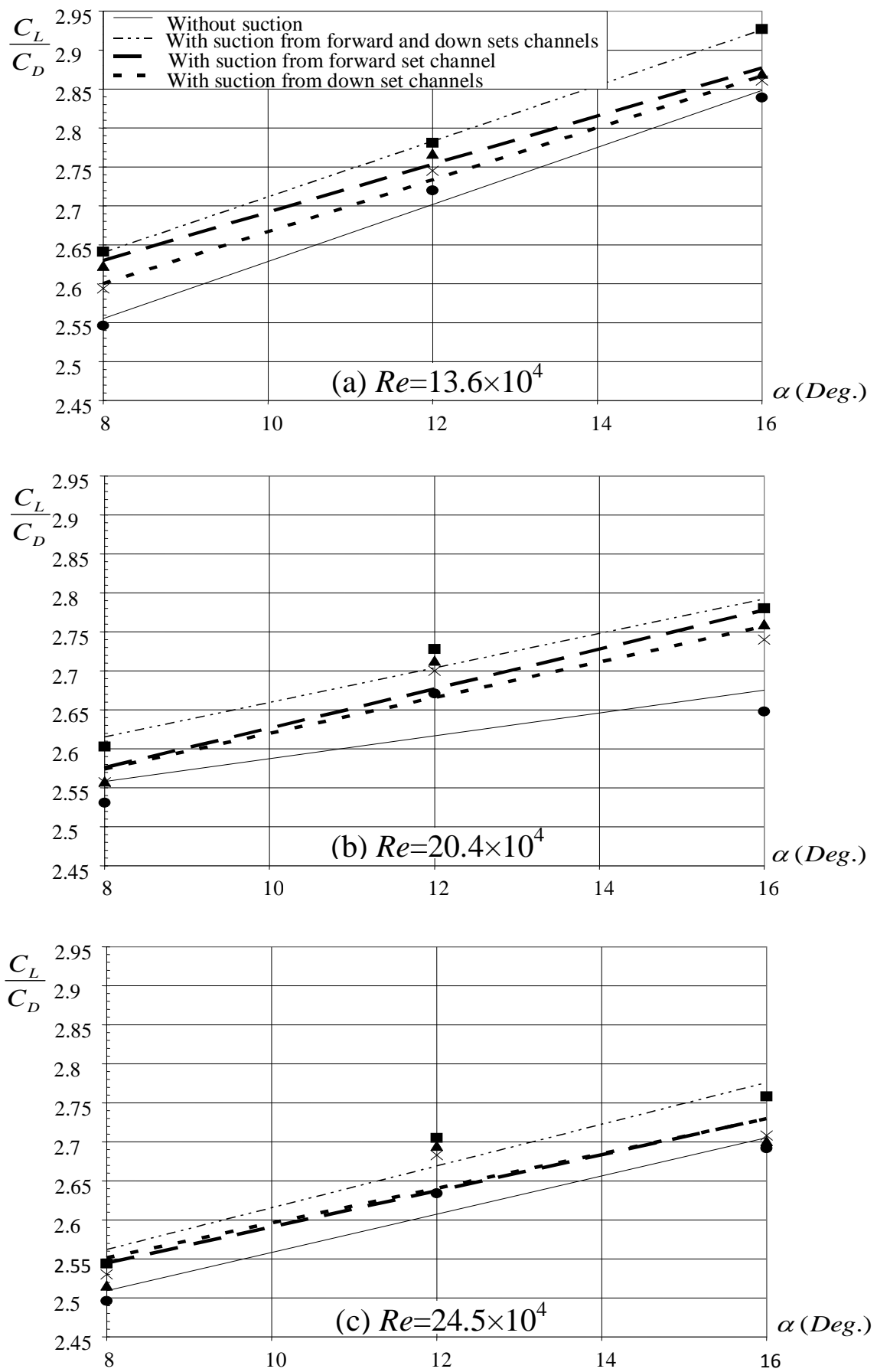

Fig. (6) Lift to Drag coefficient versus angle of attack. 


\section{Conclusions}

From the current study, it can be found that the continuous normal suction from the upper surface of the wing has positive effect on the lift coefficient, since the lift coefficient increased due to suction, and as the magnitude of suction increases, the increasing in the lift coefficient is increasing more. However, the suction has a negative effect on the drag coefficient, its values increase as the magnitudes of suction increase.

The effect of suction on the lift coefficient to drag coefficient ratio has a positive effect, as it can be seen that the ratios of lift coefficient to drag coefficient increase with suction, and their values would have a significant increase as the values of suction increase.

As the Reynolds number increases, the increasing in the lift and drag coefficients as well as the coefficient ratio are reduced, and this need an increasing in suction in order to maintain the same increasing values in lift and drag coefficient and their ratio obtained at the same Reynolds numbers.

Finally, it can be conclude from this current study that in the case of present suction lead to significant increase in the ratio of lift coefficient to drag coefficient, and this ratio play an important role in the aircraft flight characteristics (including take off and landing velocity, airport runway distance, aircraft maneuver and fuel consumption ).

\section{4- References}

1. Mohamed Gad-el-Hak, "Modern Developments in Flow Control," Applied Mechanics Reviews, Vol. 49, p. 365, 1996.

2. Garner P.L., Meredith P.T., and Stoner R.C. "Areas for Future CFD Development as Illustrated by Transport Aircraft Applications," AIAA Paper 1527, 1991.

3. M. H. Shojaefard, A. R. Noorpoor, A. Avanesians and M. Ghaffarpour, "Numerical Investigation of Flow Control by Suction and Injection on a Subsonic Airfoil," American Journal of Applied Sciences 2 (10): p. 1474, 2005.

4. H. Atik, C.-Y. Kim, L. L. Van Dommelen, and J. D. A. Walker, "Boundary-Layer Separation Control on a Thin Airfoil Using Local Suction," Under consideration for publication in J. Fluid Mech., Received 14 February 2005.

5. Ge-Cheng Zha, Wei Gao, Craig D. Paxton and Alexis Palewicz, "Numerical Investigations of Co-Flow Jet Airfoil with and without Suction," AIAA Paper 10612006.

6. Laith M. Jasim "A Numerical Study of the Unsteady Flow Separation Over an Airfoil With and Without Suction and Blowing as an Active Boundary Layer Control," Ph.D. Thesis, Mosul University, College of Engineering, Mech. Dep., 2008. 